HOW TO GET YOUR

MESSAGE ACROSS

Últimas tendencias

creativas y procesos de

innovación en campañas

de comunicación

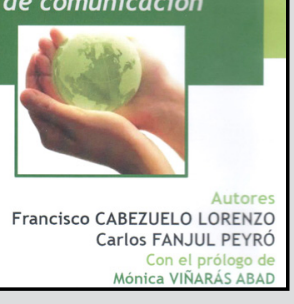

How to get your message across: Últimas tendencias creativas y procesos de innovación en campañas de comunicación

Francisco Cabezuelo Lorenzo y Carlos Fanjul Peyró Editorial Fórum XXI, Madrid

\title{
El ingenio como clave de éxito en el actual sector de la comunicación corporativa
}

$\mathrm{D}$ e la mano de la editorial Fórum XXI (Madrid), los profesores Francisco Cabezuelo Lorenzo (Universidad de Valladolid) y Carlos Fanjul Peyró (Universitat Jaume I) nos regalan una obra en formato digital que es altamente recomendable por su oportunidad en el actual sector de la comunicación corporativa. En 2013, en un contexto socio-cultural marcado por la crisis económica, ve la luz la obra “How to get your message across: Últimas tendencias creativas y procesos de innovación en campañas de comunicación", un libro en el que se acentúa la importancia del ingenio y la creatividad ante la caída de la inversión en el campo de la comunicación corporativa y publicitaria, sobre todo en los medios tradicionales. Este trabajo comienza con un breve pero brillante prólogo de la profesora Mónica Viñarás Abad (Universidad CEU San Pablo), en el que se destaca el carácter divulgativo y científicoacadémico del texto. Estas características se pueden apreciar a lo largo de las 153 páginas que componen la obra, distribuidas en dos grandes bloques -diferenciados pero perfectamente imbricados-, en los que se compilan los fundamentos de las Relaciones Públicas desde una dimensión teórico-práctica. El primero de estos bloques incluye una introducción y un contundente y conciso marco conceptual, mientras el segundo bloque presenta y analiza casos prácticos considerados por los autores como 
ejemplos de las "últimas tendencias creativas y procesos de innovación en campañas de comunicación". El trabajo se cierra con una conclusión que da coherencia al conjunto de la obra, las fichas de los autores y la bibliografía. En la parte teórica, los autores recurren a los grandes referentes en los ámbitos de la comunicación estratégica y de las Relaciones Públicas como James E. Grunig y Todd Hunt, Dennis Wilcox y Glen T. Cameron, Fraser P. Seitel, Rex Harlow, John Marston, Sam Black, Scott M. Cutlip y Allen H. Center, entre otros. Este interesante recorrido por las teorías previas permite a los profesores e investigadores Francisco Cabezuelo Lorenzo y Carlos Fanjul Peyró compartir su idea de que la comunicación estratégica y organizacional debe ser entendida como "un conjunto de acciones, cambios o funciones que implican un resultado" (p. 22). En la parte práctica, los autores ofrecen numerosos y diversos casos de éxito sin descuidar ningún ámbito de interés. Así, entre tales casos pueden encontrarse múltiples referidos a empresas con carácter lucrativo (como compañías aéreas, cadenas de comida rápida y restauración o marcas de ropa, entre otros), otros referidos a las organizaciones no gubernamentales y algunos ejemplos destacados de comunicación política (centrados en la figura de Barack H. Obama). Todos estos ejemplos se someten a una metodología de análisis del caso (case-study) y posibilitan una mejor comprensión de los conceptos teóricos expuestos en la primera parte de la obra. De esta manera, Francisco Cabezuelo Lorenzo y Carlos Fanjul Peyró satisfacen el primero de los objetivos con el que arrancan su obra "fomentar la capacidad crítica, analítica e interpretativa, aportando los conocimientos de las técnicas de investigación y procedimientos de trabajo necesarios, para conocer en profundidad el mundo de la Publicidad y las Relaciones Públicas" (p. 9). Los autores dedican la obra a sus alumnos, reconociendo así el interés pedagógico de un texto que conforma una contribución académica imprescindible. Estudiosos del amplio campo de la comunicación agradecerán un libro que destaca por su carácter divulgativo, su tono ameno, su valor didáctico y la claridad ilustrativa de sus ejemplos. Esta obra, fruto de la brillante trayectoria académica y profesional de sus autores, invita además a la reflexión y el debate con los casos creativos de publicity que presenta. En definitiva, una aportación valiosa y útil, especialmente, si se consideran las dificultades que vive actualmente el sector de la comunicación.

Carmen Llorente Barroso Universidad CEU San Pablo

ICONO14 | 2014 Volumen 12 NN$^{\circ} 2$ | ISSN: 1697-8293 | DOI: ri14.v12i2.723 